\title{
Educação em Saúde: uma Nova Abordagem
}

\author{
Health Education: A New Approach
}

\author{
Solange L'Abbate ${ }^{1}$
}

L'ABBATE, S. Health Education: A New Approach. Cad. Saúde Públ., Rio de faneiro, 10 (4): 481-490, Oct/Dec, 1994.

This article describes a series of experiences in the area of Health Education. The experiences, carried out with groups of health professionals working in institutions, begin with the social relationships in which these professionals are involved in their day-to-day work, in contact with other social agents and groups. One of the basic assumptions is that social relationships are an important aspect of the public health services provided to the population. As a result, health workers need specific training in this area to develop and improve their professional performance. The experiences show the importance of making theoretical and methodological approaches (like Educational Psychodrama and the Arvoredo Method) available to these workers. Those who have participated in such training programs have considerably improved their professional/social skills. One of the basic tenets of these approaches is the constant search for autonomy, as an essential element for people to increase awareness of themselves as individuals and as citizens, be they health care professionals or users. The experiences and methods described in this article may serve as one way of reducing the serious gaps in today's public health services.

Key words: Health Education; Professional Training; Professional Role Development

\section{INTRODUÇÃO}

Quando se pensa na atuação de qualquer profissional de saúde hoje em dia, particularmente na daquele que atua em alguma instituição ligada ao Sistema Único de Saúde(SUS), conclui-se, sem grande dificuldade, que ele enfrenta uma grave de crise em relação à sua situação de trabalho, aí incluindo nível salarial e carreira profissional, bem como a carência de recursos técnicos e materiais. A isso se acrescenta a própria situação do usuário, em estado de piora constante quanto às suas condições de vida. Mesmo estando no Brasil, cujos paradoxos parecem cada vez maiores, o que acaba banalizando perigosamente a própria noção de "crise", acaba-se por não se surpreender mais ao perce-

\footnotetext{
${ }^{1}$ Departamento de Medicina Preventiva e Social Faculdade de Ciências Médicas da Universidade Estadual de Campinas. Cidade Universitária Professor Zeferino Vaz, Distrito de Barão Geraldo, Campinas, SP, 13081-970, Brasil.
}

ber o agravamento de situações que se acreditava já terem chegado ao limite.

Na área da Saúde Pública ou Saúde Coletiva, havia fortes expectativas de que os significativos movimentos organizados de profissionais e usuários dos serviços de saúde e de outros setores da sociedade civil, sobretudo nesta última década, resultassem em algo mais do que a melhor adequação do arcabouço jurídico-político-institucional da organização dos serviços de saúde na construção do SUS, aí incluindo o papel do setor privado e a efetivação da verdadeira Seguridade Social. Esperava-se, a esta altura, que houvesse, pelo menos "a ousadia de cumprir e fazer cumprir a lei” (GED/MS, 1993).

Percebe-se, por outro lado, a necessidade de valorizar conquistas obtidas no cotidiano da atuação dos serviços de saúde, que, às vezes, parecem pequenas, mas que, na verdade, constituem importantes avanços no sentido de não se perder o já conseguido e, sobretudo, de conservar e ampliar a dimensão ética que todo profissional de saúde deve assumir na sua prática. 
É na perspectiva dessa problemática que tem sido repensada a Educação em Saúde. Um primeiro delineamento desta disciplina permite defini-la como um campo de práticas que se dão no nível das relações sociais normalmente estabelecidas pelos profissionais de saúde, entre si, com a instituição e, sobretudo com o usuário, no desenvolvimento cotidiano de suas atividades.

É possível, quanto a isso, considerar algumas premissas básicas:

1. Não se pode pensar os serviços de saúde sem refletir sobre as relações entre esses atores ou sujeitos, uma vez que qualquer atendimento à saúde envolve, no mínimo, a interação entre duas pessoas;

2. Tais relações, provavelmente, nunca ocorreram totalmente em problemas. No entanto, a atual crise do setor saúde deve estar contribuindo, e muito, para aumentar as dificuldades;

3. Qualquer tipo de atuação visando à melhoria dos serviços de saúde deve capacitar os profissionais de saúde para a busca constante do aperfeiçoamento das relações sociais que se desenvolvem no dia-a-dia dos serviços, numa perspectiva crítica de visualizar, com naturalidade, os problemas advindos da convivência humana, em qualquer situação na qual ela ocorra;

4. O aperfeiçoamento dessa dimensão deve ser considerado tão necessário quanto as outras capacitações nas áreas da Epidemiologia e do Planejamento/Administração, e, mais ainda, pode, muitas vezes, precedê-las ou ser abordada de forma concomitante;

5. Finalmente, é possível dispor atualmente de instrumentos adequados para desenvolver esse tipo de capacitação, desde que se apresentem oportunidades e possibilidades no nível pessoal/profissional e decisão no nível político/institucional para apreendêlos e utilizá-los.

\section{NÍVEIS DE ATUAÇÃO ABERTOS AO CAMPO DA ED̉UCAÇÃO EM SAÚDE}

Ao final de cerca de três anos de atuação junto a profissionais de saúde das mais diversas formações, é possível delimitar algumas das principais necessidades desses trabalhadores. Constata-se também algo extremamente positivo: ao explicitá-las, os profissionais têm demonstrado que a dimensão do desenvolvimento pessoal/profissional é inseparável do aperfeiçoamento da forma de atender o usuário.

É possível dividir a demanda dos profissionais pela área da Educação em Saúde em duas direções: a primeira, voltada para a instrumentalização em técnicas didático-pedagógicas, e a segunda, para o desenvolvimento do papel profissional.

Os dois tipos de demanda englobam, de maneira geral, as atividades que a outrora vem desenvolvendo, algumas, individualmente, e outras, em conjunto com profissionais do Laboratório de Comunicação e Educação em SaúdeLaces (DMPS, Laces, 1992).

\section{Instrumentalização em Técnicas Didático-Pedagógicas}

A demanda por esse tipo de capacitação deu origem ao Curso de Educação em Saúde, ministrado desde 1991, como disciplina optativa do Curso de Especialização em Saúde Pública (L'Abbate et al., 1992).

A busca dessa capacitação aparece na fala dos profissionais como necessidade de aprender a trabalhar em grupo e/ou melhorar o seu contato com o usuário nos atendimentos mais individualizados. Significa geralmente para o profissional a possibilidade de apropriar-se de técnicas em trabalho de grupo e de educação em saúde, e como tal é por ele reiteradamente reivindicada.

Como se tem acolhido essa demanda? Para responder à questão, são introduzidos alguns princípios que revelam qual tem sido a dimensão educativa considerada e vivenciada como postura inserida no conjunto das atividades dos profissionais de saúde.

Ao explicitá-los, são indicadas também algumas formas utilizadas para desenvolvê-los, demonstrando, assim, que essa maneira de trabalhar procura relacionar permanentemente os pressupostos teóricos dos quais se parte sua aproximação de situações nas quais os profissionais/alunos se vêem envolvidos no presente, estiveram envolvidos no passado ou pretendem envolver-se no futuro. 
Tais fundamentos são os seguintes:

1. Para ser educador no desenvolvimento de atividades do cotidiano não é preciso tornar-se especialista em teorias da educação, em teorias pedagógicas, ou em teoria da comunicação, mas é preciso entender algo sobre:

Primeiro, a existência de relações fundamentais entre educação e sociedade, no sentido de que toda teoria sobre educação contém uma visão de mundo e de sociedade ou, se se quiser, uma ideologia; segundo, alguns pressupostos a respeito do processo ensino-aprendizagem, considerando que grande parte do trabalho do profissional de saúde envolve transmissão de conhecimentos e orientações; terceiro, uma visão geral de como a educação em saúde tem sido desenvolvida enquanto concepção e prática nas instituições de saúde brasileiras, na medida em que estas foram sendo constituídas; quarto, a análise crítica do tipo de mensagens relacionadas à educação em saúde pelos veículos de comunicação de massa, sobretudo as televisões comerciais, podendo mesmo ter contato com produções independentes ou até planejar material próprio.

2. Os profissionais $\backslash$ alunos devem sentir-se o tempo todo sujeitos do processo educativo e, da mesma maneira, aprender a considerar sujeitos o usuário e os outros profissionais. Como sujeito, entende-se uma pessoa em busca de autonomia, disposta a correr riscos, a abrir-se ao novo, ao desconhecido, e na perspectiva de ser alguém que vive numa sociedade determinada, capaz de perceber seu papel pessoal $\backslash$ profissional $\backslash$ social diante dos desafios colocados a cada momento.

Para desenvolver melhor o que está entendendo com a noção de "sujeito", a autora recorre à perspectiva de Sartre (Coleção "Os Pensadores”, 1987), de pensar o ser humano como ser "em projeto", engajado e responsável com o que se passa ao seu redor. Mais do que preocupado, angustiado, e aqui se recorre às palavras daquele autor, quando afirma que
“O Existencialismo não tem pejo em declarar que o homem é angústia. Significa isto: o homem ligado por um compromisso e que se dá conta de que não é apenas aquele que escolhe ser, mas de que é também um legislador pronto a escolher, ao mesmo tempo que a si próprio, a humanidade inteira, não poderia escapar ao sentimento da sua total e profunda responsabilidade".

(Coleçao “Os Pensadores”, 1987)

É justamente o fato de aceitar essa angústia como parte da condição humana que permite ao homem desenvolver-se como um ser ético; para tanto, deverá estar o tempo todo construindo o seu processo de autonomia. É o que afirma Nelson Levy (1991), preocupado em conceituar o homem como ser ao mesmo tempo desejante e ético:

"A angústia com a ausência de um sentido imanente à Vida e a necessidade humana de sentido constituem o conflito que move a transcedência. E é justamente esta necessidade de viver para um sentido que motiva a atividade ética (Lery, 1991). (...) Assim os Humanos são seres éticos porque se encontram biologicamente dotados de um poder de autodeterminacão por suas finalidades subjetivas (autonomia) e, por isso, são capazes de viver a vida em uma realidade físico-imaginária (simbólica). Portanto a autonomia manifesta-se como capacidade humana de autodeterminação por leis (ou finalidades) subjetivas (grifo da autora). Leis provenientes, no fundamental, do exercício da faculdade de imaginação. Leis que apenas dependem da adesão humana a uma ordem imaginariamente instituida. Nesse caso, a autonomia exercita-se como atividade da faculdade de imaginação(...), faculdade que impregna de modo diferenciado todos os dominios da atividade humana.(...) Quando a imaginação atua no interior de uma relação cognitiva (ou manipulatória) ela deve manter-se subordinada aos encadeamentos de causas e efeitos constitutivos de um determinado objeto-coisa.(...) Mas quando éa criação de finalidades ('telos') ou causas subjetivas que está a motivar a faculdade de imaginação, esta última deve ser definida como faculdade de desejar" (grifos da autora).

(Levy, 1991) 
A longa citação é necessária para fundamentar o que se pretende com a Educação em Saúde: contribuir para o desenvolvimento dos profissionais de saúde como sujeitos autônomos que constroem essa autonomia com base na imaginação de um outro futuro, um outro porvir, diferente, qualitativamente melhor, do contexto em que se vive atualmente.

Para construir esse futuro, é preciso, por um lado, desejá-lo, "subjetivamente"/(apesar da redundância), e, por outro, traduzir esse desejo em ações do cotidiano, para afastar a tentação de fugir pelo caminho do idealismo ou do imobilismo. A questão é que as pessoas não desejam outro futuro ou não se empenham em construí-lo a partir do seu cotidiano e de acordo com esse desejo, porque não sabem; muitas vêzes não o fazem, porque não podem.

Não saber, não poder... entra-se num terreno nebuloso, na medida em que tais atitudes e predisposições não podem ser consideradas sem levar em conta que são determinadas pelos níveis do consciente e do inconsciente, $\mathrm{e}$, quanto a este último, torna-se necessário recorrer a outro referencial, como o da Psicanálise, por exemplo.

No entanto, sem falso otimismo, a autora considera que há possibilidades de avanços na construção de uma capacitação pedagógica dos profissionais de saúde, desde que se trabalhe com abordagens adequadas, assim como há também grande terreno aberto àquilo que costuma denominar genericamente "trabalho de grupo institucional”, baseado na perspectiva do socius e não do psi. Com isso, está querendo afirmar a possibilidade de realizar um trabalho de grupo no qual se coloque mais ênfase na dimensão pessoal/profissional/institucional e menos na dimensão pessoal/ psicológica, até onde seja possível considerá-las separadamente.

Trata-se de assunto controverso, sendo, mesmo, temática de investigação já iniciada (L'Abbate, 1994). Contudo, a experiência vem mostrando que é possível contribuir significativamente para que trabalhadores de saúde transformem sua vida profissional em algo mais rico, vivo e inovador, quando se criam condições para que eles se apropriem de certos recursos, que podem ser chamados genericamente de didático-pedagógicos, contanto que a própria forma de contribuir para esse processo de apropriação seja pautada numa relação entre "sujeitos desejantes em busca de autonomia" (Levy, 1991), a fim de não reproduzir a relação manipulatória.

Muito ligada à noção de sujeito está a de cidadania. A autora entende que os dois conceitos - sujeito e cidadão - são faces de uma mesma moeda. A temática da cidadania vem sendo abordada, tanto na ampla literatura especializada como na imprensa, seja em artigos, seja em comentários constatando e denunciando a falta de respeito aos direitos, o que ocorre cotidianamente na sociedade brasileira, sobretudo em relação ao setores menos privilegiados da população.

Nunca é demais insistir, porém, que, se o desenvolvimento da cidadania contém um aspecto instituído, referido ao arcabouço jurídico de qualquer estado democrático, sua realização concreta depende de práticas sociais instituintes, que no entender desta autora só podem ocorrer entre sujeitos, ou seja, entre atores sociais em relação (L'Abbate, 1990; Berlinguer, 1993). Caso contrário, haverá apenas uma relação burocrática entre funcionários e clientela, como, infelizmente, ocorre em grande parte de nossos serviços de saúde e serviços públicos em geral.

Nesse sentido - e guardando as devidas proporções quanto à ênfase, porque o autor citado refere-se às instituições psiquiátricas brasileiras, cuja situação é reconhecidamente uma das mais graves do setor saúde -, é interessante refletir no que diz Jurandir Freire Costa (1991) quanto ao funcionamento da "máquina burocrática" que dirigia e ainda dirige grande parte das instituições psiquiátricas brasileiras.

O autor usa a hipótese de que

"o exercício burocrático da profissão ou da cidadania insere os indivíduos num tipo de 'montagem perversa' das relações sociais conforme noção criada por Contardo Calligaris (1986-1988). Esta montagem possui uma economia e dinâmica própria, desvinculada da hierarquia de valores, hegemônica no imaginário social: idéia de lei; de produtividade; de excelência de trabalho; de utilidade das ações; de não desperdício de recursos, etc”. 
Tais comentários apontam para a interrelação de vários aspectos, cuja referência é preocupação deste artigo. Apostando na constituição dos indivíduos como sujeitos, que se constroem a partir da busca da autonomia, estáse também "vacinando" contra o processo burocrático que, como um polvo, tenta imobilizar todos, na prática institucional.

3. Finalmente, outro princípio geral no qual se acredita é que muito mais importante do que aprender técnicas é adquirir a postura de educador ou, explicitando melhor, estas só devem ser buscadas como recurso auxiliar ao processo educativo, porque o principal "instrumento" da relação educativa é o próprio educador.

Disso decorrem três considerações: a primeira, saber por que, como e quando utilizar, e, sobretudo, reinventar técnicas, de acordo com as condições de trabalho; buscar ajuda de manuais que já existem,e, sobretudo, não utilizar técnicas como panacéia universal ou para substituir o contato mais direto entre educador e educando; a segunda é considerar que todo recurso didático que se pretende aplicar ao outro deve ter sido experimentado anteriormente pelo próprio educador. Assim, ao enfrentar as dificudades, por exemplo, o medo de se abrir ao desconhecido, de ser espontâneo, de se expor, enfim, está-se, ao mesmo tempo, aprendendo um novo instrumento e percebendo as formas de resistência que outros poderão ter, adquirindo maior competência para acolher e lidar com as dificuldades dos outros; a terceira, a proposta didática utilizada deve estar em consonância com a postura ética do educador e permitir o desenvolvimento da criatividade, integrando as várias dimensões constitutivas de todo ser humano.

\section{Explicitando a Proposta Didático-Pedagógica}

De maneira geral, a proposta que vem possibilitando o desenvolvimento desse conjunto de pressupostos tem sido pautada basicamente no Psicodrama Pedagógico ou Psicodrama Aplicado à Educação, combinado com a Metodologia Arvoredo. Alguns dos princípios dessas abordagens são explicados a seguir.
O Psicodrama, criado por Jacob Levy Moreno, pode ser considerado "uma terapia de ação, onde o indivíduo, ao invés de relatar ao terapeuta os seus conflitos, vivencia-os através da dramatização" (Puttini, 1991). Segundo o psicodramatista Dalmiro M. Bustos,

"toda formulação moreniana é totalizadora:inclui o psicológico, o biológico, o social. Nesse sentido, é existencial (...)

Moreno formula essa totalidade, basicamente, quando nos fala do encontro, centro da proposta existencial psicodramática. Tal encontro se dá numa dimensão temporal que aparece formulada, pela primeira vez, na filosofia. Esta dimensão é o momento. Um tempo não compartimentado em passado, presente e futuro, o único tempo existencial real, porque se desdobra nos três simultaneamente". (Bustos apud Naffah-Neto, 1979)

Há, portanto, proximidade entre a abordagem proposta por Moreno e as idéias que vêm sendo colocadas até aqui. Sem entrar na discussão a respeito dos limites da psicoterapia psicodramática e das várias críticas que podem ser feitas ao Psicodrama, sobretudo quando se consideram os fundamentos de outras disciplinas, como, por exemplo, a Psicanálise, até porque isso fugiria ao propósito deste texto, a experiência de utilização de técnicas do Psicodrama para abordar a educação em saúde e o trabalho de grupo, em geral, têm sido muito promissores.

Isso porque se trabalha com o Psicodrama Pedagógico,expressão criada pela psicodramatista Maria Alícia Romaña (1987) não com a intenção de

\section{"estabelecer somente uma diferença entre aplicação didática e terapêutica da dramatização, mas sim de reconhecer uma unidade básica relativa à filosofia e fundamento de uma mesma técnica,procurando identificar,através do 'pedagógico', fundamentalmente o nosso referencial e o campo de ação do educador”.}

Em trabalho posterior, (Romaña, 1992), a autora aprofunda o conceito de Psicodrama Pedagógico, demonstrando as possibilidades de 
construção do conhecimento por meio da abordagem psicodramática. Contextualiza a obra de Moreno com outros pensadores da Educação, indicando alguns dos pressupostos teóricos e filosóficos dos quais parte. Uma das correntes fundamentais é a fenomenologia.

Almeida (1982), ao analisar a relação entre o método fenomenológico-existencial e o método do Psicodrama, assinala que, para ambos, "as conclusões são sempre provisórias. $O$ inacabar, longe de ser empecilho, é a própria definição da existência e é o que faz o método fenomenológico-existencial um método aberto" (Almeida, 1982). Daí a postura moreniana "uma resposta provoca cem perguntas".

Como a fenomenologia está presente também na filosofia existencial de Sartre, o método psicodramático utilizado como recurso didáticopedagógico é coerente com o conceito de ser humano do qual se parte, conforme referido.

$\mathrm{O}$ que esta autora tem observado na aplicação do Psicodrama é sua plasticidade, rapidez e capacidade de síntese tanto nas dramatizações como na metodologia educacional psicodramática, técnica criada por Romaña para a elaboração de conceitos,a partir de diversos níveis de aproximação com situações da realidade.

Outro aspecto muito interessante é a possibilidade que o Psicodrama oferece de trabalhar sempre a partir de aspectos que emergem do próprio grupo, possibilitando que as pessoas envolvidas se percebam como grupo de relação, o que é fundamental para qualquer trabalho educativo: como se trabalha com outros grupos, seja de usuários, de outros profissionais, de estudantes, do público em geral, etc, se o próprio indivíduo nunca vivenciou as dificuldades de refletir como tem sido sua atuação pessoal nos grupos ou equipes aos quais pertence?

Por outro lado, o Grupo Especializado de Educação Arvoredo, tendo como fundamento o conceito de Educação como "um amplo processo de desenvolvimento da pessoa, na busca de sua integração e harmonização, nos diversos níveis do físico, do emocional e do intelectual" (Filosofia do Arvoredo, s/d), tem desenvolvido estratégias específicas quanto a diferentes formas de expressão e comunicação, incluindo as da comunicação não-verbal, da ampliação da percepção e de diferentes formas de trabalhar a dinâmica de grupo. Assim, várias estratégias são colocadas à disposição do educador para que ele próprio se considere "o principal instrumento da dinâmica do ensino-aprendizagem”.

Apropriar-se dessa capacitação tem permitido aos participantes dos cursos e oficinas não apenas resgatar o seu próprio processo educativo ao longo da vida, como também estar mais preparado para entender e acolher o mesmo processo no outro. Desse modo, ambos, educador e educando, mantêm-se em constante crescimento. Além disso, a estratégia tem proporcionado a elaboração de projetos de atuação, contemplando os vários tipos de áreas, nas quais os profissionais/alunos estão envolvidos (L'Abbate et al., 1992).

\section{Desenvolvimento do Papel Profissional}

Sob esse título, a autora engloba atividades que vem desenvolvendo há cerca de dois anos junto a grupos de funcionários da Rede Básica de de Paulínia, São Paulo, constituída de centros de saúde e de um hospital de nível secundário e grupos de profissionais do Hospital das Clínicas da Universidade Estadual de Campinas (Unicamp), respondendo a solicitações dos próprios trabalhadores ou das direções das instituições.

Os grupos têm sido de dois tipos, basicamente. Um primeiro, constituído da totalidade dos funcionários de uma instituição ou setor, tratando-se, portanto de pessoas com diferentes níveis de formação (superior, médio e primário), com distintas funções e atribuições, comprometidas com um produto final que é definido pela instituição. Há, portanto, grande diversidade de papéis profissionais e ampla heterogeneidade.

Um segundo, mais homogêneo, composto de trabalhadores de um mesmo setor - Serviço Social - havendo divisão interna de trabalho - assistente social e auxiliar social - e diferenciações pelo fato de pertencer ao ambulatório, enfermaria ou pronto socorro de um hospital.

Nas duas formações, o coordenador da instituição ou setor participou da atividade. Após um número médio de 10 encontros, em geral realizados no próprio espaço institucional, todos 
os grupos, com base no que emergiu nas reuniões, elaboraram propostas de reorganização do trabalho ou setor, ou reafirmaram e revalorizaram práticas já consagradas.

Os comentários a seguir referem-se ao conjunto dessas experiências (L'Abbate, 1994), naquilo que tem apresentado de mais relevante.

Por que partir da abordagem do papel profissional? Porque se considera que as demandas por esse tipo de intervenção têm reforçado a idéia de que, partindo-se do desenvolvimento do papel profissional, se pressupõem certas garantias importantes, tais como:

1. A dimensão que dá fundamento ao trabalho, ou seja, o conceito fundante é o campo profissional, o que significa que os participantes só abordarão aspectos de sua vida pessoal se quiserem, e apenas aqueles com relação mais direta ao exercício do papel profissional.

2. Em segundo lugar, tem-se observado que a abordagem do papel profissional possibilita a abertura, com maior envolvimento e compromisso, para pensar a instituição como um todo. No caso das instituições públicas de saúde, por exemplo, refletir sobre certos conceitos básicos, quais sejam, o significado do caráter público, o direito à saúde, a concepção de saúde/ doença quando se pensa a Saúde Coletiva. Em suma, o que é atender o usuário, quando se adere a tais princípios.

A primeira preocupação é: como conceituar esse tipo de trabalho? A qual categoria pertence?

Do ponto de vista da forma, é trabalho de grupo, e a metodologia utilizada é semelhante à que foi abordada na primeira parte do texto. De maneira geral, esse trabalho pode ser inserido no tipo de intervenção institucional que René Lourau (1975) e Georges Lapassade (1989) caracterizam como "intervenção pedagógica”, apesar de incorporar também aspectos da análise de grupo e da sócio-análise,que são os outros níveis de intervenção institucional considerados por esses autores.Embora, na prática, seja impossível separar completamente os três níveis, é fundamental não confundir o conceito de onde se parte, que é o de trabalho educativo; portanto, de natureza pedagógica.

$\mathrm{Na}$ realidade, trabalhar o papel profissional abre possibilidades tanto para o espaço pessoal/ grupal como para o pessoal/institucional. Aqui a autora retoma, para desenvolver melhor, um comentário feito na primeira parte do texto e que considera de grande relevância, colocandoo enquanto questionamento: como se mesclam o trabalho pedagógico e o psicológico quando o espaço profissional é invadido pelo espaço pessoal?

Isso ocorre, sobretudo, quando emergem dificuldades de relacionamento entre pessoas que trabalham juntas. Muitas vezes, tais problemas referem-se a mal-entendidos em geral, implicância com o jeito de ser de um e de outro, insatisfação quanto à distribuição e cobrança de tarefas, desagrado com o desempenho da chefia; enfim, essas e outras situações causadoras de mágoa e constrangimento.

Ao serem expressas no grupo e pesquisadas a partir das técnicas referidas anteriormente, as situações passam a ser percebidas e re-elaboradas de outra forma pelos participantes, ou seja, com certo distanciamento e menor nível de ansiedade, facilitando a busca de soluções alternativas.

Muitas vezes, o simples fato de trazer à tona uma determinada situação que incomodava, já resolve; outras vezes, trata-se de algo muito mais profundo que não pode ser resolvido no âmbito deste tipo de trabalho, sendo necessário para alguns, participantes, a procura de psicoterapia.

$\mathrm{O}$ que se tem observado, a partir dos resgates feitos a cada encontro, é o aumento da tolerância entre as pessoas, que muitas vezes convivem o dia inteiro, em clima ruim, o que pode refletir, em última análise, na qualidade do trabalho realizado e do atendimento prestado.

Nunca é demais repetir: a referência é sempre a do "público", a do profissional, ou seja, o âmbito do "privado" é tratado com grande cuidado e sempre com o consentimento da pessoa e do grupo. Isso porque as pessoas não estão ali para fazer terapia, embora o trabalho 
até possa vir a ter uma "função terapêutica", entre aspas. Essa premissa é colocada muito claramente para o grupo desde o primeiro momento, quando se estabelece o contrato, ou seja, o compromisso mútuo dos membros do grupo com o coordenador.

A distinção, mesmo parecendo "cartesiana", é importante. Uma das diferenças seria a de que, no trabalho terapêutico, há ou é proposto que haja o envolvimento da pessoa em sua “totalidade", enquanto no trabalho educativo, e ainda mais num espaço institucional, apenas alguns aspectos são revelados. Além disso, há as especificações profissionais e o respeito à divisão de trabalho. Para cuidar do terapêutico, há o profissional com a competência adequada.

Infelizmente não se dispõem de informações sobre o que ocorreu com alguns grupos, decorrido algum tempo da realização do trabalho, sobretudo quanto à situação do grupo em relação, como dizia Moreno. Essa é uma questão da maior relevância e da maior dificuldade. Como dar continuidade a esse tipo de trabalho para manter e avançar o que se conseguiu durante aquele curto período de tempo?

Apesar dessa descontinuidade, sem esquecer que, para alguns grupos, o tempo de duração do trabalho foi suficiente, uma certeza vem sendo reforçada cada vez mais: criar espaço adequado para os profissionais de saúde olharem para o seu trabalho, poderem expressar sua perplexidade e seus sentimentos e dor diante do sofrimento, doença e morte, com os quais lidam todos os dias, pode ser muito importante para, em primeiro lugar, valorizarem a própria atividade e, em segundo, contribuir para evitar a ocorrência de duas situações extremas, ambas totalmente indesejáveis: o trabalhador cair na indiferença total que leva à burocratização ou até à "montagem perversa" já referidas, ou adquirir distúrbios mentais ou psicossomáticos sérios e muitas vezes irreversíveis.

Há, nesse sentido, algumas análises caracterizando o trabalho de muitos profissionais da área da saúde como trabalho penoso, definido como aquele que, além de produzir riscos e agressões ao organismo, provoca sérios desgastes de ordem emocional e psíquica. Ver a respeito o trabalho de Ana Maria Pitta (1990), sobre os funcionários do Hospital Matarazzo, e o de Borges e Neves (1991), sobre o trabalho da assistente social em Saúde.

Na criação desse espaço de reflexão, o papel do coordenador é, muitas vezes, "apenas" o de saber ouvir, o de ser continente para as dificuldades que o grupo traz. Aí é preciso treinar-se, ou estar atento a um tipo de "escuta analítica", que acolhe sem interpretar e, assim, permite ao grupo tratar de questões que, sozinho e nas reuniões específicas para definir estratégias de trabalho, não consegue. Pretende-se, em última instância, que, o mais rapidamente possível, o grupo possa dispensar esse "alter ego" e caminhar sozinho ou contando com algum tipo de supervisão.

Ainda em relação ao cruzamento do trabalho pedagógico com o organizacional, quando o espaço profissional é invadido pelo espaço institucional mais amplo, é possível tecer alguns comentários.

Vem sendo observando que as mudanças no nível da organização e do processo do trabalho que surgem como necessidades do grupo são mais facilmente implementadas, porque o compromisso é muito maior, embora aí haja dois aspectos a considerar: o primeiro é que, antes de jogar a responsabilidade na direção do serviço, postura muito comum em nossa cultura institucional, sobretudo a dos serviços públicos, há muito a ser feito pelo próprio grupo e que só depende dele; o segundo é que, quando se trata de algo que depende do acordo da direção da instituição, pode ocorrer e tem ocorrido que nem sempre a direção aceita as propostas de mudança, apesar do empenho em incentivar o desenvolvimento da postura de negociador, na medida em que essa competência também faz parte do papel profissional.

Trata-se de um outro aspecto que é o do compromisso da direção da instituição com o trabalho que está sendo feito. Esse é um problema fundamental que surge e poderá surgir sempre nesse tipo de abordagem: até que ponto a direção da instituição, mesmo que tenha partido dela o pedido para o trabalho de desenvolvimento profissional, está disposta a assumir e implementar o que se decide no grupo quando se trata de medidas que ultrapassam as possibi- 
lidades do próprio grupo, sobretudo quando essa direção não concorda com tais medidas? Aqui, entramos na esfera do poder e do controle sobre os destinos, os objetivos e até sobre os trabalhadores de uma determinada organização. Terreno minado, portanto, e que precisa ser enfrentado com outras estratégias.

Assumindo tais desafios, a autora considera que sistematizar e divulgar esse conjunto de questionamentos e indagações, decorreu da necessidade de explicitar um conjunto de preocupações que, pensa, não são apenas suas, mas de todo um grupo de profissionais da área da Saúde Coletiva, que, tendo a cabeça na academia, sente necessidade de ter os pés nos serviços de saúde. Afinal, é neles que as relações entre aqueles que estão construindo $o$ atendimento à saúde ou à doença acontecem, e, em última análise, o que se deseja é que nesse acontecer cotidiano haja transformações significativas no sentido ético e de justiça que deve pautar toda relação social mediante a qual se presta um serviço quando as pessoas envolvidas são cidadãos.

\section{AGRADECIMENTOS}

A algumas pessoas com as quais tenho compartilhado essas idéias e dialogado continuamente: Lia Fukui, Elizabeth L.M. Smeke, Julieta H. Oshiro, lígia M.P.M. Santos, stela Fava e Arthur Hyppolito de Moura.

\section{RESUMO}

L'ABBATE, S. Educação em Saúde: uma Nova abordagem. Cad. Saúde Públ., Rio de Janeiro, 10 (4): 481-490, out/dez, 1994.

Este artigo desenvolve reflexão sobre um conjunto de experiências na área de Educação em Saúde, entendida como campo privilegiado de práticas que ocorrem no nível das relações sociais estabelecidas cotidianamente pelos profissionais de saúde, no âmbito institucional, envolvendo os diversos atores presentes. Assumindo que é sobretudo por meio dessas práticas que se presta o atendimento de saúde ao usuário, torna-se necessário colocar à disposição do profissional de saúde. Capacitação didático-pedagógica específica e a possibilidade de participação em estratégias, visando ao desenvolvimento do papel profissional. Nesse sentido, as experiências analisadas apontam para a importância de se dispor de abordagens teórico-metodológicas adequadas, como a do Psicodrama Pedagógico e da Metodologia Arvoredo, mediante as quais tem sido possível instrumentalizar os profissionais interessados em aperfeiçoar-se nesse campo. Ao mesmo tempo, dados os pressupostos das abordagens referidas, tem sido possível demonstrar ser imprescindível adotar postura ética de busca constante da autonomia como pressuposto básico do processo de construção de sujeitos|cidadãos, sejam eles outros profissionais ou usuários. Entre as possibilidades trazidas por tal abordagem e os limites da atual constituição dos serviços de saúde, situa-se a proposta em pauta.

Palavras-chaves: Educação em Saúde; Capacitação Didático-Pedagógica; Desenvolvimento do Papel Profissional

\section{REFERÊNCIAS BIBLIOGRÁFICAS}

ALMEIDA, W. C., 1982. Psicoterapia Aberta: o Método do Psicodrama. São Paulo: Ágora.

BERLINGUER, G., 1993. O direito à vida e a ética da saúde. Lua Nova, 30: 121-143.

BORGES, L. H. \& NEVES, L. C. S., 1991. Especificidade e Condições de Trabalho do Assistente Social da Área de Saúde da Secretaria Municipal de Saúde do Município de São Paulo. São Paulo: Diesat. (Mimeo.)

BUSTOS, D. M., 1979. Prólogo. In: Psicodrama. Descolonizando o Imaginário (A. Naffah-Neto, org.), pp. 11-12, São Paulo: Brasiliense.

COLEÇÃO “OS PENSADORES”, 1987. Sartre (J. A. M. Pessanha, Seleção de Textos). $3^{\mathrm{a}}$ ed., São Paulo: Abril Cultural. (Coleção Os Pensadores)

COSTA, J. F., 1991. Psiquiatria burocrática: duas ou três coisas que sei dela. In: Clínica do Social: Ensaios (L. T. Aragão, org.), pp. 39-74, São Paulo: Escuta. 
DMPS (Departamento de Medicina Preventiva e social); FCM (Faculdade de Ciências Médicas) \& UNICAMP (Universidade Estadual de Campinas), 1992. Proposta de Criação do Laboratório de Comunicação e Educação em Saúde(Laces). Campinas: Unicamp. (Mimeo.)

FILOSOFIA DE TRABALHO DO ARVOREDO, s $\backslash$ d. Documento do Arvoredo, Grupo Especializado em Educação. São Paulo. (Mimeo.)

L'ABBATE, S., 1990. O Direito à Saúde: da Reivindicação à Realização. Projetos de Política de Saúde em Campinas. Tese de Doutorado, São Paulo: Faculdade de Filosofia, Letras e Ciências Humanas, Universidade de São Paulo.

, 1994. Relatos de Experiências sobre o Desenvolvimento do Papel Profissional em Instituições de Saúde: um Espaço de Possibilidades. Relatório Preliminar. Campinas. (Mimeo.)

L'ABBATE, S.; SMEKE, E. L. M. \& OSHIRO, J. H., 1992. A educação em saúde como um exercício de cidadania. Saúde em Debate, 37: 81-85.
LAPASSADE, G., 1989. Grupos, Organizações e Instituições. $3^{\mathrm{a}}$ ed., Rio de Janeiro: Francisco Alves.

LEVY, N., 1991. Desejo... o Lugar da Liberdade (um ensaio ético-politico). São Paulo: Debates.

LOURAU, R., 1975. A Análise Institucional. Petrópolis: Vozes.

MS (Ministério da Saúde, Grupo Especial para Descentralização), 1993. Descentralização do SUS: prioridade do MS. Saúde em Debate, 38: 04-17.

PITTA, A. M. F., 1990. Hospital. Dor e Morte como Ofício. São Paulo: Hucitec.

PUTTINI, E. F., 1991. Origens e justificativas do projeto. In: Psicodrama na Educação (E. F. Puttini, org.), pp. 13-16, Ijuí: Inijuí.

ROMAÑA, M. A., 1987. Psicodrama Pedagógico. $2^{\mathrm{a}}$ ed., Campinas: Papirus. 1992. Construção Coletiva do Conhecimento Através do Psicodrama. Campinas: Papirus. 